\title{
PLANTAS ORNAMENTAIS NA FRONTEIRA OESTE DO RIO GRANDE DO SUL - PERFIL DOS CONSUMIDORES
}

Luana da Silva Cadore ${ }^{1}$, Luciana Pinto Paim ${ }^{2}$, Alessandra Pletsch ${ }^{3}$, Caroline Farias $^{2}$ Barreto $^{4}$, Luciana Zago Ethur ${ }^{5}$

1 Mestranda do Programa de Pós-Graduação em Agrobiologia da Universidade

Federal de Santa Maria (luanascadore@yahoo.com.br). Santa Maria - Brasil

2 Mestranda do Programa de Pós-Graduação em Fitotecnia da Universidade Federal do Rio Grande do Sul. Porto Alegre - Brasil

3 Engenheira Agrônoma na empresa C. Vale Cooperativa Agroindustrial. Tapera Brasil

4 Doutoranda do Programa de Pós-Graduação de Agronomia da Universidade Federal de Pelotas. Pelotas - Brasil

5 Professora Doutora do Campus Itaqui da Universidade Federal do Pampa. Itaqui Brasil

Recebido em: 03/10/2016 - Aprovado em: 21/11/2016 - Publicado em: 05/12/2016

DOI: 10.18677/EnciBio_2016B_076

\section{RESUMO}

O Rio Grande do Sul figura entre os estados com maior número de consumidores de plantas ornamentais do país, superando as médias nacionais em até quatro vezes, porém existe uma grande diversidade no comércio de ornamentais entre as cidades. Desta forma, objetivou-se diagnosticar o perfil dos consumidores de plantas ornamentais no município de Itaqui, na fronteira oeste do Rio Grande do Sul. A pesquisa foi desenvolvida no município de Itaqui. Foi aplicado um questionário semiestruturado para 407 pessoas, individualmente, próximo as floriculturas da cidade. Os consumidores de plantas ornamentais são predominantemente do gênero feminino, sendo a maioria destes na faixa etária entre 21 e 40 anos de idade, com escolaridade de ensino médio completo e ensino superior incompleto, cuja renda fica em torno de 3 a 5 salários mínimos. Os produtos são adquiridos predominantemente em floriculturas. A compra se dá principalmente para presentear, no valor acima de $R \$ 31,00$, porém as compras não são frequentes. Conclui-se que o gênero feminino é responsável pelas maiores aquisições em floriculturas de Itaqui. A idade dos consumidores está dentro da faixa dos ativos economicamente e a compra é motivada por datas comemorativas, por isso não é frequente. A aquisição de flores e plantas ornamentais para decorações de ambientes de casas e de escritórios ainda é restrita as faixas mais abastadas da população.

PALAVRAS-CHAVE: comércio, flores, floricultura.

\section{ORNAMENTAL PLANTS IN WEST FRONTIER OF STATE OF RIO GRANDE DO SUL - PROFILE OF CONSUMERS}

\footnotetext{
ABSTRACT

The state of Rio Grande do Sul ranks among the states with the highest number of consumers of ornamental plants in Brazil, getting averages larger than nationals up ENCICLOPÉDIA BIOSFERA, Centro Científico Conhecer - Goiânia, v.13 n.24; p.813 2016
} 
to four times. Therefore, there is a great diversity in trade of ornamental plants between cities. Thus, this study aimed to diagnose the profile of consumers of ornamental plants in the city of Itaqui, in the western border of the state of Rio Grande do Sul. The research was conducted in the city of Itaqui. It was applied a questionnaire to 407 people, individually, near of flower shops. The consumers of ornamental plants are predominantly women; the most of consumers have age between 21 and 40 years; they have incomplete education at higher school; their incomes are around 3 to 5 times the minimum wage and they purchase products in flower shops. The purchase is mainly for gift, worth over $R \$ 31,00$, but purchases are infrequent. Then, it can be concluded that the women are responsible for the largest acquisitions in flower shops of Itaqui. The age of the consumer is within the range of assets economically and the purchase is motivated by holidays; so, purchases are infrequent. The acquisition of ornamental plants for home and office environments decorations is still restricted to the more affluent sections of the population.

KEYWORDS: trade, flowers, flower shops.

\section{INTRODUÇÃO}

As plantas ornamentais fazem parte de um setor econômico que cresce constantemente, pois fazem parte do dia a dia dos brasileiros, com versões de cores, tamanhos e preços, dependendo das condições financeiras e culturais. A floricultura comercial, como atividade profissional e empresarial de produção, comércio e distribuição de flores e plantas com finalidade ornamental, representa um dos mais promissores segmentos do agronegócio brasileiro contemporâneo (JUNQUEIRA \& PEETZ, 2011). O crescimento fica na ordem de 8 a $10 \%$ ao ano nas quantidades e de 12 a 15\% nos valores comercializados (MENEGAES et al. 2015). Segundo ANEFALOS et al. (2010), estes índices, estão acima dos níveis médios de crescimento do PIB nacional, os quais comprovam a alta possibilidade de crescimento sustentável da atividade no país.

De acordo com JUNQUEIRA \& PEETZ (2014), existem no Brasil, 7.800 produtores de flores e plantas ornamentais; observando-se aumento do número de produtores no Rio Grande do Sul (RS), que passou de 560 produtores em 2008 para 1.519 em 2013. O Rio Grande do Sul destaca-se, também, como grande consumidor de flores e plantas ornamentais, sendo que na região central do estado o mercado varejista é caracterizado por dois modos distintos quanto ao objetivo principal de comercialização - primeiro, detém o foco na venda de produtos florais e ornamentais, caracterizado por floriculturas, e o segundo é representado pelos estabelecimentos em que as flores e plantas ornamentais fazem parte de um conjunto de ofertas, abrangendo lojas agropecuárias, feiras hortigranjeiras e supermercados (MENEGAES et al. 2015).

Partindo destes pressupostos, pode-se inferir a necessidade de pesquisas mais detalhadas sobre a demanda da floricultura brasileira, principalmente para 0 Rio Grande do Sul, dando ênfase na fronteira oeste do estado, onde os dados sobre o consumo de plantas ornamentais são irrisórios. Nesse sentido, objetivou-se diagnosticar o perfil dos consumidores de plantas ornamentais do município de Itaqui, na fronteira oeste do Rio Grande do Sul.

\section{MATERIAL E MÉTODOS}

O trabalho foi desenvolvido no município de Itaqui, localizado na fronteira oeste do Estado do Rio Grande do Sul, tendo como municípios limítrofes brasileiros: 
Uruguaiana, São Borja, Maçambará, Manoel Viana e Alegrete e como limítrofes argentinos: La Cruz e Alvear; com área de $3.406 \mathrm{Km}^{2}$; com 38.159 habitantes. A economia do município é baseada praticamente no cultivo do arroz e na pecuária (IBGE, 2016).

O instrumento empregado nesta pesquisa consistiu em um questionário semiestruturado com questões fechadas e abertas, voltado às preferências de plantas ornamentais pelos consumidores. Foram um total de 11 questões referentes às plantas ornamentais, de acordo com os seguintes critérios: dados pessoais, motivo, local e frequência de compra, preferência por ornamentais, as plantas que possuem em casa, faixa de preço e opinião sobre o cultivo na cidade.

O questionário foi aplicado para 407 pessoas ao acaso, individualmente, perto das três floriculturas existentes na cidade. Os participantes, após aceitarem participar da pesquisa, receberam uma breve explanação sobre a mesma. $O$ preenchimento dos questionários foi auxiliado pelos entrevistadores, sempre que solicitado. Posteriormente a realização das entrevistas, os dados foram tabulados e analisados por meio de estatística descritiva.

\section{RESULTADOS E DISCUSSÃO}

A floricultura no Rio Grande do Sul encontra dificuldade para seu estabelecimento, principalmente na região Sul do estado, devido à questão cultural, onde prevalecem como principais atividades agrícolas o cultivo de arroz irrigado e a pecuária de corte (TERRA \& ZÜGE, 2013). A fronteira oeste do Estado do RS, também apresenta essas características agrícolas. Dessa forma, observa-se que principalmente no município de Itaqui as praças e parque não possuem o cultivo de plantas com flores vistosas, como ocorre em outras cidades do estado, mas sim de árvores e arbustos. Nesse sentido, o perfil de consumidores de plantas ornamentais é importante, para nortear os investimentos na área, seja pelas floriculturas e supermercados ou pela agricultura familiar na produção de mudas, plantas de corte e plantas envasadas. As entrevistas mostraram uma acentuada predominância do gênero feminino no consumo de ornamentais, perfazendo $72 \%$ dos entrevistados, enquanto que o gênero masculino obteve $28 \%$ dos entrevistados. Com isso, presume-se que as mulheres são as consumidoras potenciais deste ramo.

As flores ou as plantas ornamentais sempre foram vistas como fazendo parte do universo feminino, porém sabe-se que esse comportamento está se modificando aos poucos entre a população. Contudo, os resultados apontam no sentido de as mulheres serem as protagonistas no momento da compra de plantas ornamentais na fronteira oeste do RS.

Segundo CAMARGO \& D'OLIVEIRA (2014), as mudanças sociais, culturais e econômicas que ocorreram no país nas últimas décadas colocaram as mulheres como agentes e sujeitos, em novos papéis em todas as esferas de suas vidas, desde o casamento até o mercado de trabalho. Ainda segundo as autoras, estas novas relações influenciam diretamente no funcionamento do mercado e no consumo. Neste sentido, as mulheres estão, atualmente, com condições econômicas para consumir e esse poder de compra fica evidenciado nos resultados do presente trabalho. Além do que, as floriculturas da cidade de Itaqui deveriam apropriar-se das indicações aqui relacionadas e apostarem no universo feminino, trazendo novas tendências e opções de produtos que estejam relacionados com as vendas motivadas para presentear ou decorar (Tabela 1). 
TABELA 1 - Perfil dos consumidores e sua motivação de compra de plantas ornamentais na cidade de Itaqui - RS.

\begin{tabular}{lc}
\hline Característica & $(\%)^{\star}$ \\
\hline Faixa Etária & 13 \\
10 a 20 anos & 27 \\
21 a 30 anos & 22 \\
31 a 40 anos & 17 \\
41 a 50 anos & 14 \\
51 a 60 anos & 7 \\
Acima de 60 anos & \\
\hline Escolaridade & 10 \\
Fundamental incompleto & 10 \\
Fundamental completo & 8 \\
Médio incompleto & 28 \\
Médio completo & 26 \\
Superior incompleto & 17 \\
Superior completo & 1 \\
Pós-graduação & \\
\hline Renda Familiar & 21 \\
1 salário mínimo & 29 \\
2 salários mínimos & 38 \\
3 a 5 salários mínimos & 7 \\
5 a 7 salários mínimos & 5 \\
Acima de 7 salários mínimos & \\
\hline Local de Compra & 0 \\
Armazém & 0 \\
Feira livra & 12 \\
Supermercado & 74 \\
Floricultura & 14 \\
Supermercado e outros & \\
\hline Frequência de Compra & 12 \\
1 vez ao ano & 22 \\
2 a 3 vezes ao ano & 34 \\
Frequentemente & 32 \\
Raramente & \\
\hline Motivo da Compra & 48 \\
Presente & 25 \\
Cultivo & 19 \\
Decoração & 8 \\
Outros & \\
\hline Faxa de Preço & \\
\hline & \\
\hline
\end{tabular}

\section{Faixa de Preço}

0 a 10 reais 13

11 a 20 reais 23

21 a 30 reais $\quad 24$

Acima de 31 reais $\quad 40$

Preferência de compra

Flores 43

Folhagens $\quad 7$

Ambas $\quad 50$

ENCICLOPÉDIA BIOSFERA, Centro Científico Conhecer - Goiânia, v.13 n.24; p.816 


\begin{tabular}{ll}
\hline Hábito de compra ou cultivo em Itaqui & 49 \\
Sim & 36 \\
Não & 15 \\
Algumas & \\
\hline
\end{tabular}

*407 entrevistados.

De acordo com à faixa etária, constatou-se que a maior parte dos entrevistados se enquadrava entre duas frequências, de 21 a 40 anos, somando $49 \%$ (Tabela 1). Essa faixa etária é considerada economicamente ativa na sociedade (MARCHESE et al., 2004). Para escolaridade, as entrevistas demonstraram que os principais consumidores possuem ensino médio completo e superior incompleto, correspondendo a $28 \%$ e $26 \%$, respectivamente (Tabela 1). Contudo, estudos apontam que o consumo tende a aumentar com um maior grau de instrução (MARCHESE et al., 2004).

Já referente a faixa salarial, foi possível observar que $38 \%$ dos consumidores de plantas ornamentais encontram-se entre 3 a 5 salários mínimos (Tabela 1). De acordo com SANTOS et al. (2013), a maior parte dos consumidores de ornamentais da cidade de Santa Maria - RS, ficam acima da renda de cinco salários mínimos, diferindo do presente estudo.

Referente ao local de compra, verificou-se que $74 \%$ dos entrevistados adquirem suas plantas em floriculturas (Tabela 1), condizendo assim, com CASTRO (1998), o qual relata que as flores destinadas para presente, são vendidas em lojas de flores (floriculturas). Já OLIVEIRA et al. (2011), relatam em sua análise sobre o mercado de flores e plantas ornamentais comercializadas em Lavras-MG, que o espaço para comercialização se agrupa em floriculturas comerciais e floriculturas de auto-serviço em supermercados, sendo que o tempo médio de existência das empresas é de 6,4 anos, isto devido a informalidade com que o setor conduz as relações comerciais.

Com relação à frequência de compra deve-se salientar que somente $34 \%$ dos entrevistados compra frequentemente e $32 \%$ raramente adquire tal produto (Tabela 1). Segundo SANTOS et al. (2013) a compra de produtos em floricultura na cidade de Santa Maria - RS é considerada esporádica por $71 \%$ dos entrevistados. Confirmando os estudos de MARQUES \& CASTRO FILHO (2003) os quais revelam que a demanda por plantas ornamentais no Brasil, concentra-se basicamente nas datas festivas, principalmente dia das mães, dia dos namorados e finados.

A frequência de compra de plantas ornamentais está diretamente relacionada com a motivação da compra, pois $66 \%$ da população de Itaqui compra esporadicamente (1 ou 2 vezes ao ano ou raramente) e a principal motivação, para presentear, é de $48 \%$ dos entrevistados (Tabela 1). Ressalta-se que o consumo para uso próprio, per capita de flores no Brasil é baixo se comparado com o mercado europeu, correspondendo à 40\% e 65\%, respectivamente (IBRAFLOR, 2016).

Quanto à faixa de preço, $40 \%$ dos entrevistados pagam acima de $R \$ 31,00$ por plantas ornamentais, e pela análise realizada esse fato deve-se a motivação da compra, porque $48 \%$ dos entrevistados adquirem para presente (Tabela 1). Porém, é importante salientar que os entrevistados que indicaram renda de 1 salário mínimo (21\%), no geral, indicaram que a faixa de preço de compra seria de até $\mathrm{R} \$ 10,00 \mathrm{e}$ que compravam 1 vez ao ano ou raramente. Com isso, pode-se inferir que a aquisição de plantas ornamentais para decorações de ambientes de casas e de escritórios ainda é restrita as faixas mais abastadas da população. 
Em relação à escolha por alguma espécie de ornamental, os entrevistados apontaram que tem preferência por plantas com flores em $43 \%$ dos casos, comparado-se a $7 \%$ de folhagens (Tabela 1). Quando questionados sobre o hábito de comprar ou cultivar plantas ornamentais pelos moradores da cidade de Itaqui, os entrevistados em sua maioria (49\%) responderam que a cidade possui o hábito (Tabela 1). Porém, houve relatos que existe dificuldade de se conseguir conservar jardins, principalmente públicos, devido a ação de vândalos. Além disso, alguns entrevistados realizaram observações que a cidade de Itaqui, quando comparada com cidades do centro do Estado, de colonização europeia como Nova Petrópolis e Santa Cruz do Sul, deixa a desejar quanto ao cultivo de plantas ornamentais, tanto com relação a decoração pública quanto aos jardins particulares. Ressaltam que não existe tradição do cultivo de plantas ornamentais na fronteira oeste do Estado do Rio Grande do Sul.

Quando abordados sobre as plantas ornamentais que os entrevistados possuíam em suas residências, as espécies de plantas com flores mais citadas foram: rosas, crisântemo, lírio, violeta e orquídeas; e as espécies de folhagens: samambaia, ficus e pingo de ouro.

Salienta-se que o cultivo e comercialização de flores e plantas ornamentais é uma atividade em expansão, a qual ainda encontra dificuldades de estabelecimento na cidade de Itaqui, muitas vezes por quesito cultural. Porém, com o desenvolvimento deste trabalho, foi possível observar que a floricultura vem ocupando espaço e está demarcando seu lugar no mercado local.

\section{CONCLUSÕES}

A análise do perfil dos consumidores de plantas ornamentais de Itaqui-RS evidenciou que o gênero feminino é responsável pelas maiores aquisições em floriculturas. A idade dos consumidores está dentro da faixa dos ativos economicamente e a compra é motivada por datas comemorativas, por isso não é frequente. A aquisição de flores e plantas ornamentais para decorações de ambientes de casas e de escritórios ainda é restrita as faixas mais abastadas da população.

\section{REFERÊNCIAS}

ANEFALOS, L.C.; TOMBOLATO, A.F.C.; RICORDI, A. Panorama atual e perspectivas futuras da cadeia produtiva de flores tropicais: o caso do antúrio. Revista Brasileira de Horticultura Ornamental, v.16, n.1, p. 107-111, 2010. Disponivel em: <http//dx.doi.org/10.14295/rbho.v16i1.518> doi: 10.14295/rbho.v16i1.518

CAMARGO, M.A.S.; D'OLIVIERA, M.C. Female consumption as reflective stardardization: breaking reifying paradigms. International Journal of Science Commerce and Humanities, v. 2, n. 4, p. 290-301, 2014. Disponível em: < http://www.ijsch.com/journaluk/Archives>

CASTRO, C. E. F. Cadeia produtiva de flores e plantas ornamentais. Revista Brasileira de Horticultura Ornamental, v.4, n.1, p. 1-46, 1998. Disponível em: <http://dx.doi.org/10.14295/rbho.v4i1.238> doi: 10.14295/rbho.v4i1.238

JUNQUEIRA, A.H.; PEETZ, M.S. Panorama socioeconômico da floricultura no Brasil. 
Revista Brasileira de Horticultura Ornamental, v.17, n.2, p.101-108, 2011. Disponível em: http:<//dx.doi.org/10.14295/rbho.v17i2.704> doi: 10.14295/rbho.v17i2.704

JUNQUEIRA, A.H.; PEETZ, M.S. O setor produtivo de flores e plantas ornamentais do Brasil, no período de 2008 a 2013: atualizações, balanços e perspectivas. Revista Brasileira de Horticultura Ornamental, v.20, n.2, p. 115-120, 2014. Disponível em: http:<//dx.doi.org/10.14295/rbho.v20i2.727> doi: 10.14295/rbho.v20i2.727

IBGE - Instituto Brasileiro de Geografia e Estatística, 2016. Disponível em: http://cidades.ibge.gov.br/xtras/temas.php?lang=\&codmun=431060\&idtema=16\&sear $\mathrm{ch}=\| \mathrm{s} \% E D$ ntese-das-informa\%E7\%F5es. Acesso em: 03/06/2016.

IBRAFLOR - SCHOENMAKER, K. Palavra do presidente: Crise, medidas e olímpiadas. Informativo IBRAFLOR, v.68, ano 7, p. 1, 2016.

MARQUES, R. W. C.; CASTRO FILHO, J. V. Avaliação da sazonalidade do mercado de flores e plantas ornamentais no Estado de São Paulo. Revista Brasileira de Horticultura Ornamental, v. 9, n. 2, p. 143-160, 2003. Disponível em: http:<//dx.doi.org/10.14295/rbho.v9i2.178> doi: 10.14295/rbho.v9i2.178

MARCHESE, J.A. et al. Perfil dos consumidores de plantas medicinais e condimentos do município de Pato Branco (PR). Horticultura Brasileira, v.22, n.2, p.332-5, 2004. Disponível em:<http://dx.doi.org/10.1590/S010205362004000200034> doi: 10.1590/S0102-05362004000200034

MENEGAES, J.F.; BACKES, F.A.A.L.; BELLÉ, R.A.; BACKES, R.L. Diagnóstico do mercado varejista de flores de Santa Maria, RS. Revista Ornamental Horticulture, v.21, n.3, p.291-298, 2015. Disponível em: <http://dx.doi.org/10.14295/oh.v21i3.629> doi: $10.14295 /$ oh.v21i3.629

OLIVEIRA, J.M.S.R.; GRZYBOVSKI, D.; SANTOS, A.C. Estratégia de competitividade do mercado de flores e plantas ornamentais: um estudo multifocal. Revista Conexão Ciência, v.6, n.2, p.121, 2011. http://periodicos.uniformg.edu.br:21011/periodicos/index.php/testeconexaociencia/art icle/view/94/121

SANTOS, N.Z.; KIRCHNER, R. M.; SAIDELLES, A.P.F.; LHAMBY, A. Perfil dos consumidores de produtos ornamentais no município de Santa Maria/RS. Revista Eletrônica em Gestão, Educação e Tecnologia Ambiental - REGET, v.13, n.13, p.2644-2651, 2013. Disponível em: <http://dx.doi.org/10.5902/223611707972> doi: $10.5902 / 223611707972$

TERRA, S.T.B.; ZÜGE, D.P.P.O. Floricultura: a produção de flores como uma nova alternativa de emprego e renda para a comunidade de Bagé-RS. Revista Conexão UEPG, v.9, n.2, p. 342-353, 2013. Disponível em:< http://dx.doi.org/10.5212/conex\%C3\%A3o.v9i2.5014> doi: 10.5212/conex\%C3\%A3o.v9i2.5014 